\title{
Product Design Improvement Using Human-Computer Interaction Method Based on Modal Analysis
}

\author{
Lei Liu, Hongying Liu and Aijun Ma \\ China Astronaut Research and Training Center, Beijing, China
}

\begin{abstract}
A new kind of product design improvement method was proposed, which was mainly based on modal analysis using human-computer interactive way. And it was used in design improvement of an aerospace assembly to verify the effectiveness. The method made full use of the advantages of human and computer in product design and the work was mainly focused on modal analysis by computer and structure modification by human-computer interaction method. The final design got a better solution than the initial design as the results showed that the base frequency increased by $34.7 \%$ from $43.2 \mathrm{~Hz}$ to $58.2 \mathrm{~Hz}$ after design improvement and the vibration feature improved a lot. Also the experimental results were close to the simulation results with the relative error was $2.5 \%$. The human-computer method can save cost and time and can provide a reference for other design of new products at the same time.
\end{abstract}

\section{Introduction}

With the development of society and industry, more and more products will be designed and produced. In the design phase of products, a lot of factors should be considered. And in the aerospace field, one of most important factors is vibration environment [1]. Although people wish the structure of the product can be the most suitable in the initial process of the development, the products either cannot satisfy the constraints or have large useless material allowance constantly at the beginning $[2,3,4]$.

In the original ways, people produce the test specimen product and do the experiment based on the test part under the given test environment [5]. If the test pieces cannot satisfy the environment, people will improve the design and reproduce the test specimen product and test on it in a series of cycles. Obviously, the original product design means will expenditure a big amount cost and waste too much time at the same time. But with the development of CAD/CAE/CAM software, people can modify the structure in the product design software such as Pro/E, CATIA, SolidWorks and so on. Besides, by analysis of finite element software, people can find the weak point of the structure and improve the design in the software $[6,7,8]$. By cycles of design improvement, people will get a better solution than the initial design, and only need to do verified experiment on the final product. Based on the development of $\mathrm{CAD} / \mathrm{CAE} / \mathrm{CAM}$ software, we proposed a human-computer interaction method $[9,10]$ of product design improvement.

\section{Product design improvement using human-computer interaction method}

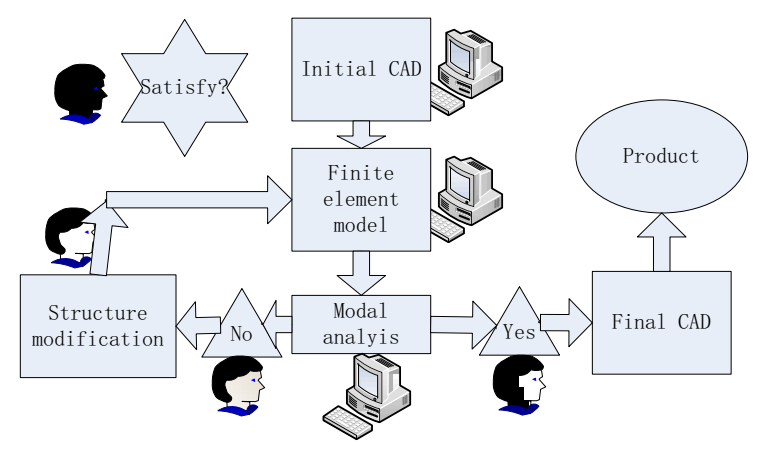

Figure 1. Flow chart of human-computer interaction method.

In this paper, a new kind of product design improvement using human-computer interaction method based on modal analysis was proposed and could be described as Fig. 1. As people design the product, they usually have initial CAD in the preliminary stage. Then they can import the initial CAD to finite element software such as HyperMesh, PATRAN, ANSYS and so on to get the finite element model. By modal analysis, the vibration feature and vibration frequency of the structure will be achieved. Then the weak point of the structure will be got by analysis of the vibration feature and people can improve the design by modification of the structure [11]. The biggest characteristic of the method is human-computer interaction; human and computer play a different part in the design improvement progress, but have sufficient interaction to finish the final job. Human not only work in the structure modification phase, but also help in the decisions whether the design is satisfied or not with the optimum scheme.

3 Improvement design of an aerospace assembly 


\subsection{Descriptions of the aerospace assembly}

The aerospace assembly was consist of external framework and internal function products. As the internal function products were hard to modify, then the improvement work was mainly focused on the external framework which was consist of thin-walled beams. The objective was increasing the base vibration frequency and improving the vibration feature. To get a better look at the improvement point of the framework and in considering of privacy, the following figures just displayed the framework of the aerospace assembly and hided part of internal function products. But in the design and computing phase, all parts had been considered. The initial CAD could be described as Fig. 2. This phase was mainly finished based on computer using CAD software.

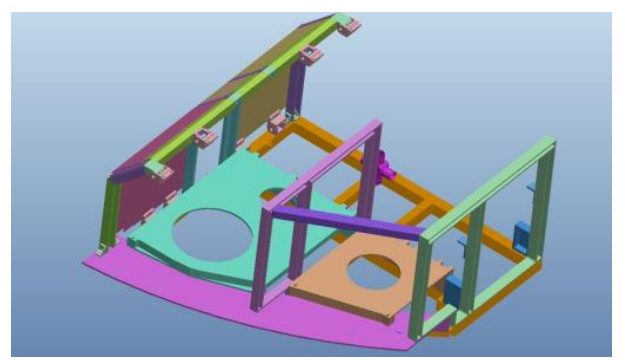

Figure 2. Initial CAD of the aerospace assembly.

\subsection{Creating finite element model}

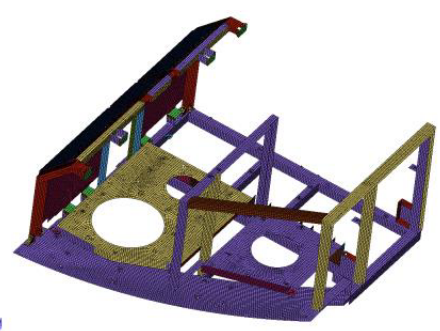

Figure 3. Initial finite element model of the aerospace assembly (model a).

Then the initial CAD was imported to the finite element software. And the finite element model of the frame was divided by two dimension grids while the internal function products were divided by three dimension grids. Also this phase was mainly finished based on computer and the finite element model can be described as Fig. 3.

\subsection{Modal analysis}

As the finite element model was achieved, then modal analysis could be conducted and the first vibration feature could be got as fig.4. And the base frequency of the assembly was $43.2 \mathrm{~Hz}$ which was less than the desired value. Worse still, vibration of the cared internal function products displayed as black circles in fig .4 was too large to satisfy the demand. Also this phase was mainly finished based on computer by finite element software.

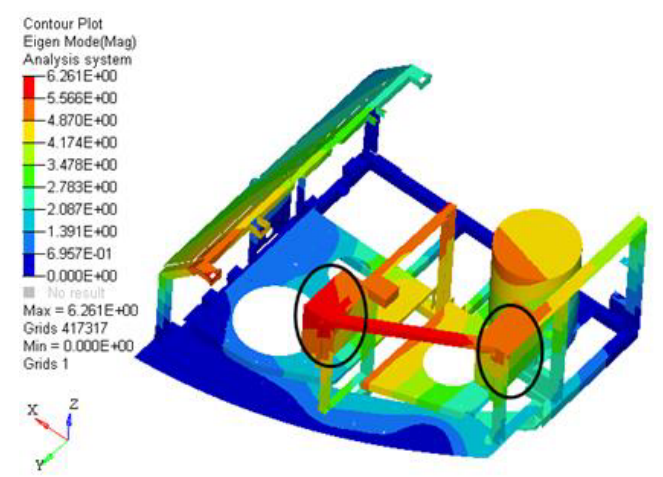

Figure 4. First vibration feature of the aerospace assembly (model a).

\subsection{Improvement of the finite element model based on modal analysis}

Then the design could be improved in the finite element software by human-computer interaction, which meant that modal analysis and structure modification was conducted in an interactive style and the assembly would make a better performance by cycles of structure modification again and again. In this phase, the work was finished by human-computer interaction. The improvement design of the aerospace assembly in the finite element software can be described as Fig. 5.

The design model of the aerospace assembly was improved from model ' $a$ ' to model ' $d$ ' after a cycle of structure modification. And Table 1 listed the base vibration frequency of four structures and the change of cared parameters.

Table 1. Parameters change chart of four structures.

\begin{tabular}{cccccc}
\hline Parameters & $\begin{array}{c}\text { Topo } \\
\mathrm{a}\end{array}$ & $\begin{array}{c}\text { Topo } \\
\mathrm{b}\end{array}$ & $\begin{array}{c}\text { Topo } \\
\mathrm{c}\end{array}$ & $\begin{array}{c}\text { Topo } \\
\mathrm{d}\end{array}$ & $\begin{array}{c}\text { Rate } \\
\text { change }\end{array}$ \\
\hline $\begin{array}{c}\text { Base } \\
\text { frequency } / \mathrm{Hz}\end{array}$ & 43.2 & 44.2 & 45.8 & 58.2 & $+34.7 \%$ \\
\hline
\end{tabular}
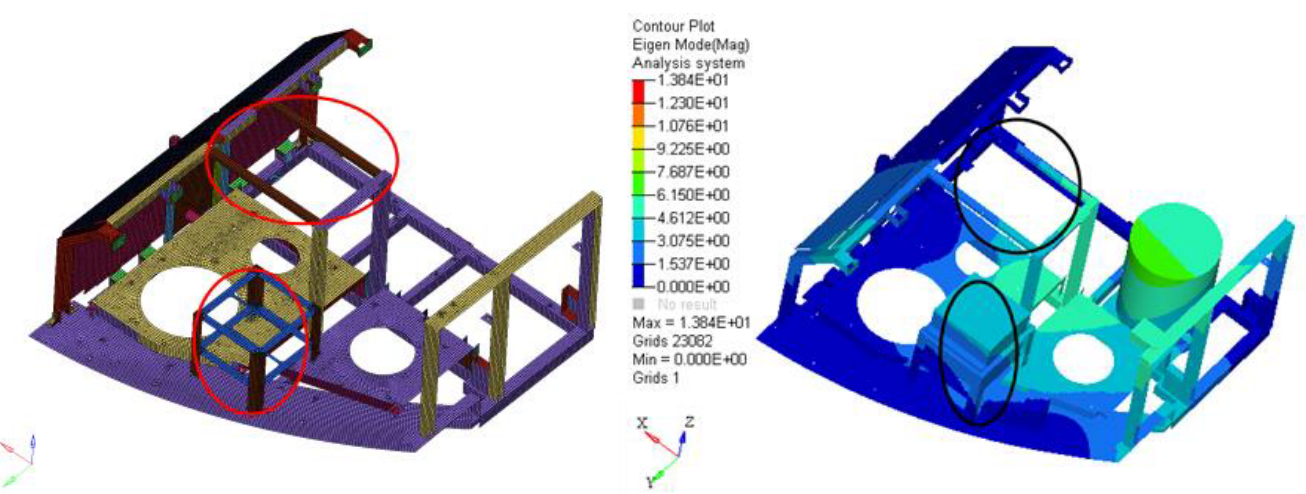

Model b (44.2Hz) 


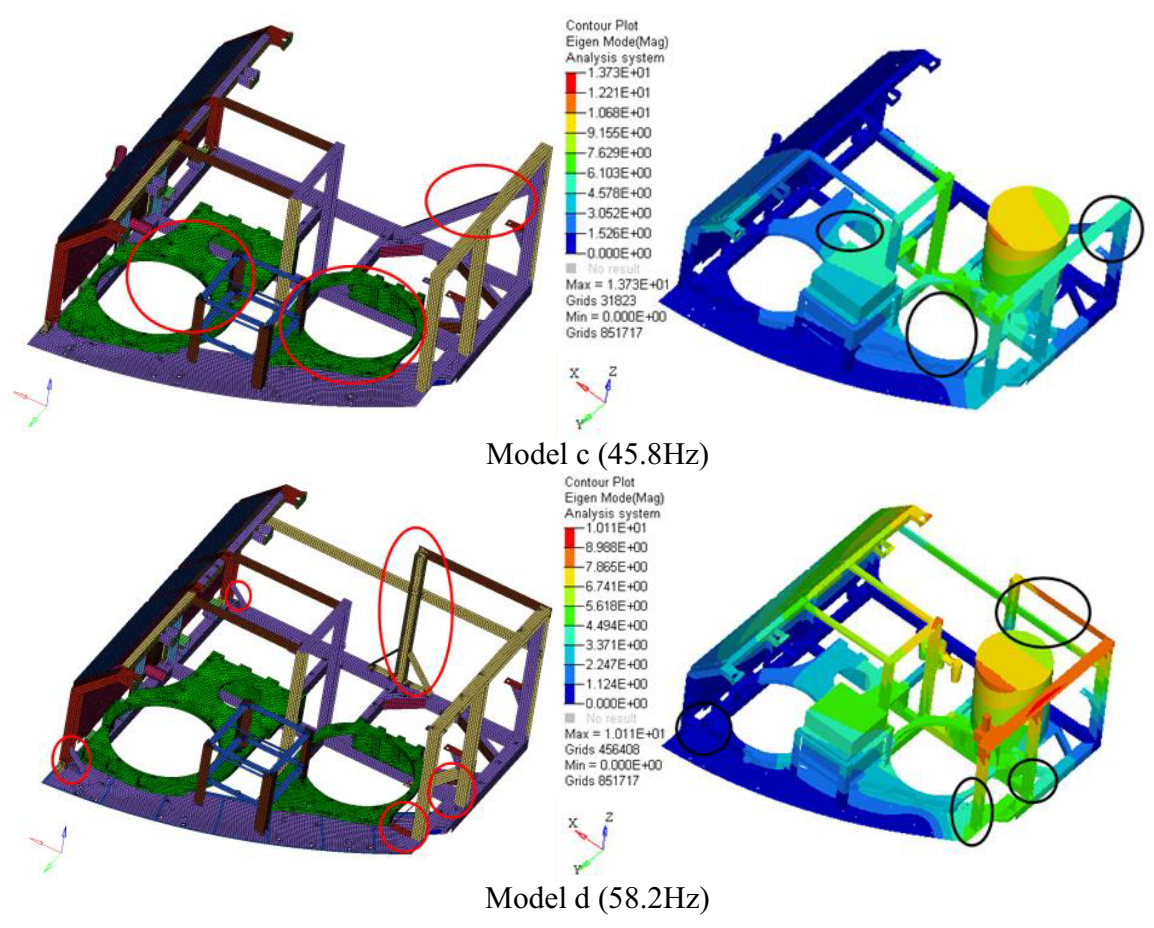

Figure 5. Improvement design of the aerospace assembly in finite element software.

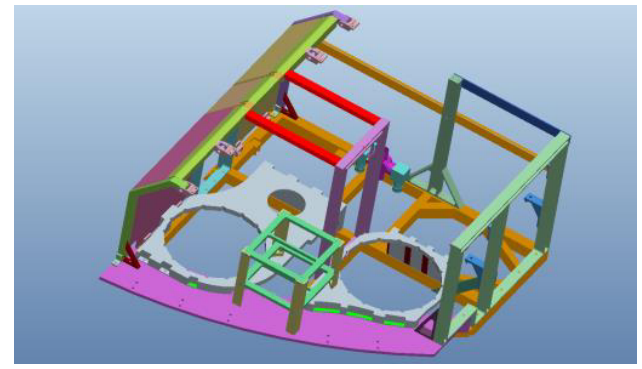

Figure 6. Final CAD of the aerospace assembly.

\subsection{The final CAD and product.}

By cycles of improvement by human-computer interaction method, the final finite element model could satisfy the requirement by modal analysis results. Besides, the base frequency of the final model improved from $43.2 \mathrm{~Hz}$ to $58.2 \mathrm{~Hz}$ and the weak points had been modified, so model ' $d$ ' could be regarded as the final finite element model [12]. Then we used the Pro/E software to generate the final $\mathrm{CAD}$ described as Fig. 6 and produced the product.

\subsection{Experimental results.}

The final product was produced based on the final CAD of Fig. 6. And vibration environment experiment was established on the $10 \mathrm{t}$ platform vibrator. The experimental results of the base vibration frequency was $59.7 \mathrm{~Hz}$. Table 2 listed the comparison of the simulation results with the experimental results.

\section{Results \& discussion}

The simulation data from table 1 showed that the base frequency of aerospace assembly had improved from
$42.3 \mathrm{~Hz}$ to $58.2 \mathrm{~Hz}$ after human-computer interaction product design improvement based on modal analysis, and the rate change between final model ' $\mathrm{d}$ ' and initial model ' $a$ ' was $34.7 \%$, which showed that the improvement design made a good performance and the effect was obvious.

And the experimental results of the base frequency of the real product from table 2 was $59.7 \mathrm{~Hz}$ comparing to the simulation results which was $58.2 \mathrm{~Hz}$, and the relative error was about $2.5 \%$, which proved the effectiveness of the simulation analysis by finite element software. From this case, the following conclusion could be drew that product design improvement using human-computer interaction method could make a great contribution in design of similar product, and was not limited to the aerospace product.

Table 2 Comparison of the simulation results and the experimental results.

\begin{tabular}{llll}
\hline $\begin{array}{l}\text { Analysis } \\
\text { situation }\end{array}$ & $\begin{array}{l}\text { Simulation } \\
\text { results }\end{array}$ & $\begin{array}{l}\text { Experimental } \\
\text { results }\end{array}$ & Relative error \\
\hline Value & $58.2 \mathrm{~Hz}$ & $59.7 \mathrm{~Hz}$ & $2.5 \%$ \\
\hline
\end{tabular}

\section{Conclusions}

In this paper, a new kind of product design improvement using human-computer interaction method was proposed and was used to an aerospace assembly to verify the effectiveness. The results showed that the design improvement increased the base frequency by $34.7 \%$ from $43.2 \mathrm{~Hz}$ to $58.2 \mathrm{~Hz}$ and the vibration feature improved a lot. Also the experimental results were close to the simulation results with the error was $2.5 \%$. The method was mainly based on modal analysis on the finite element model by computer and structure modification by human-computer interaction. The method made full use of the advantages of human and computer in product 
design and could get a better solution than the initial design. In a word, the human-computer method can save cost and time and can provide a reference for other design of new products at the same time. This human-computer ideology might also be used for other fields such as key engineering material and so on.

\section{Acknowledgement}

Funded by the manned space flight project of China was greatly appreciated.

\section{References}

1. Tibert, Gunnar. Deployable tensegrity structures for space applications. Royal Institute of Technology (2002)

2. Nguyen, Trung Thanh, Shengxiang Yang, and Juergen Branke. "Evolutionary dynamic optimization: A survey of the state of the art." Swarm and Evolutionary Computation 6 (2012): $1-24$.

3. Schlegel, Martin, and Wolfgang Marquardt. "Detection and exploitation of the control switching structure in the solution of dynamic optimization problems." Journal of Process Control 16, 3 (2006): 275-290.

4. Åkesson, Johan, K-E. Årzén, Magnus Gäfvert, Tove Bergdahl, and Hubertus Tummescheit. "Modeling and optimization with Optimica and JModelica. org-Languages and tools for solving large-scale dynamic optimization problems." Computers \& Chemical Engineering 34, 11 (2010): 1737-1749.
5. Wegener, Joachim, A. Baresel, and H. Sthamer. "Evolutionary test environment for automatic structural testing." Information \& Software Technology 43, 14 (2001): 841-854.

6. Peeters, Bart, and Guido De Roeck. "Reference-based stochastic subspace identification for output-only modal analysis." Mechanical systems and signal processing 13, 6 (1999): 855-878.

7. Ewins, David J. Modal testing: theory and practice. Letchworth: Research studies press, 6 (1995)

8. Peeters, Bart, and Guido De Roeck. "Stochastic system identification for operational modal analysis: a review." Journal of Dynamic Systems, Measurement, and Control 123, 4 (2001): 659-667.

9. Preece, Jenny, Yvonne Rogers, Helen Sharp, David Benyon, Simon Holland, and Tom Carey. Human-computer interaction. Addison-Wesley Longman Ltd., (1994)

10. Cohen, Ira, Fabio G. Cozman, Nicu Sebe, Marcelo C. Cirelo, and Thomas S. Huang. "Semisupervised learning of classifiers: Theory, algorithms, and their application to human-computer interaction." Pattern Analysis and Machine Intelligence, IEEE Transactions on 26, 12 (2004): 1553-1566.

11. Kitazaki, Satoshi, and Michael J. Griffin. "A modal analysis of whole-body vertical vibration, using a finite element model of the human body." Journal of Sound and Vibration 200, 1 (1997): 83-103.

12. Nefske, D. J., J. A. Wolf, and L. J. Howell. "Structural-acoustic finite element analysis of the automobile passenger compartment: a review of current practice." Journal of Sound and Vibration 80, 2 (1982): 247-266. 